\title{
ENTREVISTA COM YAO FENG
}

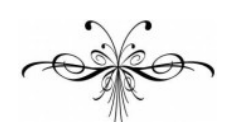

YAO FENG / RAQUEL ABI-SÂMARA ${ }^{1}$

$\mathrm{Y}$

ao Jingming ${ }^{2}$ é professor associado no Departamento de Português da Universidade de Macau (UM), onde atua sobretudo no Mestrado em Estudos da Tradução (chinês-português). Começou a traduzir literatura de expressão portuguesa na década de 1980, logo após concluir a graduação em Língua Portuguesa no Instituto de Línguas Estrangeiras de Pequim, atual Universidade de Estudos Estrangeiros de Pequim. Suas primeiras experiências com tradução de poesia aconteceram também naquele momento, em que se sentia, como afirma em uma de suas reflexões sobre seu papel de tradutor, corajoso o suficiente para assumir uma tarefa considerada impossível, "tal como diz um provérbio chinês: 'o bezerro recém-nascido não teme o tigre"”. Continua: "Sem medo, e com um grande entusiasmo pela poesia, dediquei-me de todo o coração ao trabalho como uma formiga a roer um osso duro. Embora duro consegui concretizá-lo” (Jingming, 2011:147). Refere-se à publicação de sua primeira antologia de poetas portugueses, que reuniu Mário Sá-Carneiro, Miguel Torga, Eugénio de Andrade, entre outros. Esses poetas, conta Yao, "começaram a habitar a língua chinesa pela minha mão ainda frágil. Para eles, será habitável esta terra nova? Não faço a mínima ideia, mas o certo é que eles continuam a respirar ali porque até hoje ainda não apareceu outra versão nova para os acolher” (idem). Essas primeiras experiências despertaram seu gosto pela tradução de poesia, e foram apenas os primeiros passos deste que é considerado atualmente um dos mais prestigiados tradutores de poesia de língua portuguesa para o chinês. Desde os anos 1980, Yao Jingming vem dedicando-se continuamente à prática e à reflexão da tradução poética. Seu livro mais recente de poemas traduzidos foi lançado em 2012, com o título 白色上的白色 (Branco no Branco, de Eugénio de Andrade, Editora Livros do Meio, Macau).

Como todo tradutor é um sujeito histórico, assim como define Henri Meschonnic em sua perspectiva histórico-materialista da tradução (Pour la Poétique II. Épistémologie de l'Écriture - Poétique de la Traduction, 1973), Yao Jingming e sua proximidade com a cultura lusófona não deixa de contar parte de

\footnotetext{
${ }^{1}$ Doutora em Letras pela Universidade do Estado do Rio de Janeiro, é professora do Departamento de Português da Universidade de Macau.

${ }^{2}$ Yao Jingming assina seus trabalhos poéticos e criativos, e parte de seus ensaios e artigos acadêmicos, com o pseudônimo Yao Feng.
} 
um capítulo da história da China. Yao nasceu em Pequim, em 1958, onde viveu até o início dos anos 1990, quando se muda e se estabelece em Macau. Aos nove anos de idade, ao terminar os estudos primários, Yao "foi escolhido" por professores, conforme conta, para estudar espanhol em uma escola secundária subordinada ao Instituto de Línguas Estrangeiras de Pequim. Havia quatro opções de idiomas na escola: russo, inglês, francês e espanhol. Yao e mais cerca de 30 alunos foram destinados, por assim dizer, ao estudo de língua espanhola. "Eram aulas de cor vermelha", conta Yao, com bastante humor. A primeira frase que aprendeu em espanhol foi: “¡Viva el Presidente Mao!” O contexto era a Revolução Cultural na China (1966-1976), anos de grande conturbação política. Os textos de leitura e todo material didático usado nas aulas de espanhol eram de temática comunista, preconizando a eliminação dos latifundiários, repugnando a opressão dos operários, da classe trabalhadora etc. Foram sete anos de estudo secundário nessa escola. Ao final, todos os alunos graduados foram levados para o campo rural, próximo de Pequim, a fim de serem reeducados pelos camponeses, os “mestres da vida”. Foi uma experiência de um ano no campo, trabalhando junto com os colegas no plantio de arroz, comandados por duas camponesas de meia-idade, que, na ocasião da colheita do arroz, os acordavam às cinco horas da manhã, para o início da jornada. Foi com humor, e muitas piadas entre si, que os estudantes viveram aquela experiência de "reeducação". O final de sua estada no campo coincide com a reforma política na China, ao final da Revolução Cultural. Logo a seguir, Yao presta os exames nacionais para ingressar na universidade. "Somente os politicamente corretos tinham o direito de fazer esses exames”, lembra Yao. Na universidade (Instituto de Línguas Estrangeiras de Pequim) gradua-se em Língua Portuguesa, e, ao concluir o curso, já começa a trabalhar, por seis anos, no Instituto de Literatura Estrangeira de Pequim, onde vai realizar suas primeiras traduções profissionais de prosa e poesia de língua portuguesa. Segue para Lisboa no final dos anos 1980, para trabalhar na Embaixada da China. Lá publicou seu primeiro livro de poemas em português, Nas asas do vento cego (1989). Ao voltar de Lisboa, vive ainda um ano em Pequim, em atividades ainda ministeriais, antes de se mudar para Macau. Começou a lecionar na Universidade de Macau, onde fez mestrado em Língua e Cultura Portuguesas. Sua dissertação de mestrado, A poesia clássica chinesa: uma leitura de traduções portuguesas, foi publicada pela Coleção Estudos de Macau (Universidade de Macau, 2001). Doutorou-se em Literatura Comparada e Literatura Universal pela Universidade de Fudan, Shangai, em 2005.

Yao Jingming, além de tradutor e acadêmico, é um poeta bastante prestigiado na China. Acaba de ser indicado para receber um dos mais importantes prêmios de poesia na China, Prêmio do Contributo Cultural Aurora, 曙光文化貢 獻獎, considerado de grande credibilidade entre os poetas, inclusive pelo fato de ser uma premiação de iniciativa privada. No entanto, como poeta, é conhecido não como Yao Jingming, mas sim como Yao Feng, pseudônimo que passou a usar para assinar seus poemas a partir de 2001. Nos últimos anos vem assinando Yao Feng não só nos poemas como também em suas traduções de poesia, artigos e ensaios acadêmicos sobre tradução e poesia. Desde 2012, Yao atua como vice-presidente do Instituto Cultural de Macau (ICM), importante órgão de divulgação e preservação da cultura de expressão portuguesa e de promoção do diálogo entre a cultura lusófona e a cultura chinesa. Apesar de ser um poeta contemporâneo, Yao Feng não deixa de seguir uma tradição de grandes poetas clás- 
sicos chineses, que, assim como Bai Juyi (772-846), ocuparam postos elevados no funcionalismo estatal na China. Vale notar que Yao Feng não precisou prestar os exames imperiais para entrar na vida pública, mas seus conhecimentos e sensibilidade para poesia, arte e cultura lusófonas e chinesas decerto contribuíram para que fosse requisitado a ocupar o atual posto. Os exames imperiais na China clássica, que permitiam a entrada no funcionalismo e a ascenção ao mandarinato, exigiam dos candidatos que fizessem duas provas: uma sobre os Cinco Clássicos confucianos (Ming Jing), outra sobre Textos Literários (Jin Shi). Este último, explica o tradutor de Bai Juyi para o português, António Graça de Abreu, "incluía a composição de alguns $f u$, versos irregulares rimados, questões sobre princípios da moral de Confúcio e teses sobre gestão e administração estatal” (Abreu, p. 16). Yao Feng não compõe fu, mas sim versos livres. A liberdade e a fluidez de seus versos, de notável leveza e sutil ironia, aparecem tanto nos poemas que compõe como nos que traduz. Suas reflexões sobre tradução de poesia, por vezes também poéticas, recorrem frequentemente a imagens para falar da teoria e da práxis da tradução. E encerra-se aqui esta apresentação do tradutor Yao Feng com uma passagem de seu texto "Traduzir um poema: por ser poema e para ser poema”:

Diz-se que o tradutor é um escravo a servir os dois reis: a língua de partida e a língua de chegada. Uma missão difícil! Como é que um escravo se pode manter fiel simultaneamente aos dois reis sem trair um ou outro? Felizmente, os reis em questão não são totalitários, não acusam nem matam o escravo quando são mal servidos, apesar de tal fato ocorrer com muita frequência. Um escravo que mantém a dupla fidelidade deve conhecer bem a alma e o corpo de ambos. No entanto, pela minha experiência como escravo, mesmo que queira servi-los de igual boa vontade, na prática não consigo ser imparcial, e afinal o que consigo fazer é servir bem um com o objetivo de servir melhor o outro; neste caso, normalmente é a minha língua materna que na maioria dos casos é a língua de chegada. Enfim, são os leitores da língua de chegada que acordam a tradução com a sua leitura. Contudo, durante o processo de descodificação, codificação e harmonização dos dois aspectos aparentemente inconciliáveis, não me apetece ser escravo absolutamente fiel, passivo e obediente. Dentro das fronteiras e do possível, o tradutor precisa de gozar de certa autonomia. (Yao, 2012:148-9) 
RAquel Abi-SÂMara: Yao Feng, pseudônimo de Yao Jingming, é o nome com que assina seus poemas, escritos tanto em chinês quanto em português. Yao Jingming é o nome com que assina seus artigos e ensaios acadêmicos. Ao traduzir um poema, seja do português para o chinês, ou vice-versa, quem traduz? Yao Jingming ou Yao Feng? A pergunta abrange um aspecto explícito e outro implícito. Com relação ao aspecto explícito: qual o nome do tradutor, nas fichas catalográficas e nas capas dos livros de poesia que você traduziu do português para o chinês? Com relação ao aspecto implícito: é o acadêmico Yao Jingming ou o poeta Yao Feng que atua, quando você traduz um poema? Em outras palavras: o que determina a qualidade e o bom resultado de uma tradução de poema: o conhecimento específico sobre a teoria da tradução e/ou a experiência do ofício poético (e aqui refiro-me tanto à experiência do poeta quanto do leitor assíduo de poesia)?

YAO FENG: Então é assim: eu não gosto muito do meu nome chinês quando assino os meus poemas. Primeiro, porque é um nome extenso, composto por três caracteres (姚京明), e depois, é um nome tão normal, nada poético, por isso não gosto de usá-lo ao publicar meus poemas em chinês. Mas, a comunidade de língua portuguesa, no caso, conhece Yao Jingming. Por isso publiquei livros de poemas assinados por Yao Jingming, como por exemplo A noite deita-se comigo (Guimarães: Pedra Formosa, 2001). Há dois anos, publiquei In Brief, um livro de poemas meus traduzidos para o inglês por um grupo de estudantes da Universidade de Macau, e usei meu pseudônimo, Yao Feng, para assinar não só os poemas como também as fotos contidas no livro. Atualmente, quando publico, seja em português ou em chinês, gosto cada vez mais de dar os créditos a Yao Feng. A tradução chinesa que fiz recentemente do livro do poeta português Eugénio de Andrade, Branco no Branco (Macau: Livros do Meio, 2012), que ficou com o título 白色上的白色, está com o nome Yao Feng. Mas essa questão dos nomes tem sido realmente um pouco confusa. No início de junho, fui convidado pela Universidade Nova de Lisboa para participar de um seminário sobre a minha poesia. O título do evento era: "Uma leitura ecológica dos poemas de Yao Feng, in Brief”. No poster de divulgação, o título do seminário vinha acompanhado de uma foto minha. Amigos meus que vivem em Lisboa, e que me conhecem como Yao Jingming, dirigiram-se à organização do evento para dizer que havia um erro na divulgação, pois o poeta que aparecia na fotografia era Yao Jingming, mas o nome que ali constava era de Yao Feng (risos). Isso gera muita confusão. Por isso agora tenho a tendência de uniformizar, de passar a assinar, sempre que possível, apenas Yao Feng. Como poeta chinês, tenho aparecido sempre com essa "etiqueta”, Yao Feng, uma espécie de marca (risos).

Em chinês, sobretudo na década de 1980, publiquei várias traduções de poemas, sempre assinadas, portanto, como Yao Jingming, como é o caso da antologia Uma coletânea de poemas modernos de Portugal, em parceira com Sun Chengao (Beijing: China Translation \& Publishing Corporation, 1992). Se calhar, começei a usar o pseudônimo Yao Feng a partir de 2001. Daí comecei a compor e a publicar muitos poemas na China continental, e assim os chineses ficaram a conhecer um poeta de Macau que se chama Yao Feng, em vez de Yao Jingming. Aliás, na China ninguém conhece o poeta Yao Jingming. Ah, e para brincar com os leitores online, em 2003 e 2004, também usei o nome Hei Zhongming, que pode ser traduzido literalmente por "Luz dentro da escuridão" 
(Hei/黑=escuro, Zhong/中=dentro, no meio do escuro e Ming/明=luz ). Por isso minha poesia, na internet, ficou conhecida inicialmente sob esse nome. Mas nenhum chinês tem esse nome. Hei/黑 (escuridão), quer dizer preto, portanto ninguém tem "escuro" ou "preto" como sobrenome. Portanto, é um nome literário, não existe como sobrenome.

R.A.S.: O livro de poemas Um barco remenda o mar, que reúne dez poetas chineses contemporâneos (SP: Martins Fontes, 2007), foi organizado por Régis Bonvicino e Yao Feng, e um dos dez poetas incluídos na antologia é o próprio Yao Feng. que também figura como um dos principais tradutores. Por que, nesse caso, a tradução e a edição/organização do livro é de Yao Feng e não de Yao Jingming? Já faz parte de seu desejo de uniformização de sua assinatura como poeta, tradutor, ensaísta, acadêmico e também editor?

YAO FENG: Então tenho de começar por falar do outro editor desse livro, Régis Bonvicino. Eu conheci esse poeta paulista online, por acaso, e a partir daí passamos a nos comunicar por e-mails. Ele conheceu-me, portanto, como Yao Feng, ele não sabia, mas agora sabe, quem era Yao Jingming (risos), por isso, claro, tive que trabalhar com ele como Yao Feng (risos).

\section{R.A.S.: Quais os poetas de lingua portuguesa que você traduziu para o chi- nês?}

Yao Feng: Traduzi Fernando Pessoa, Eugénio de Andrade, Ramos Rosa, Carlos Drummond de Andrade (gostei imenso dele, queria traduzi-lo mais), Sophia de Mello Breyner Andresen. Fiz uma antologia de poemas de Sophia Andresen, (索 菲娅诗选/ Poems of Sophia Andresen) publicado pelo Instituto Cultural de Macau junto com uma editora chinesa. O livro faz parte de uma coleção chamada "Biblioteca básica de autores portugueses”. O livro de Eugénio de Andrade, Outro nome da terra, que reúne 50 poemas, integrou a mesma coleção. Na década de 1980, traduzi junto com meu professor de português na ocasião, Sun Chengao (孙成敖), uma antologia de poesia moderna portuguesa, que reunia mais de 30 poetas, entre eles, Fernando Pessoa, Mário de Sá Carneiro, Miguel Torga. Cada poeta tinha cerca de quatro poemas. Se calhar, foi a primeira antologia de poetas portugueses publicada em chinês.

Traduzi Drummond, mas nenhum livro, cerca de 20 a 30 poemas, entre eles "Retrato de família” e o poema curto "No meio do caminho", sobre o qual escrevi um pequeno artigo. Esse poema e artigo provocaram discussões no âmbito da literatura chinesa, no sentido de “o que quis dizer esse poeta?”. Quando não se conhece o contexto do poeta, assim como do modernismo brasileiro, fica mesmo difícil compreendê-lo. E o poema às vezes é tão simples, não é mesmo? Eu tentei fazer uma leitura própria desse poema.

Gosto muito de Drummond. Traduzi também algumas frases dele sobre literatura, sobre amor, ele é impecável, é um poeta que tem que ser traduzido para o chinês. Ele escreve em português, mas é tão diferente com relação aos poetas portugueses, é uma linguagem muito própria e, ao mesmo tempo, representa aquilo que pertence aos brasileiros, tem um sabor, sem dúvida uma coisa 
que é muito própria do Brasil. Sua posição face à vida, face à morte, ao amor, é muito interessante, difere da poesia portuguesa. Não é uma poesia necessariamenete leve, mas é escrita de uma forma leve, tem uma máscara muito alegre, mas é uma poesia profunda. Olha, portanto, aquele poema "No mármore de tua bunda". Foi escrito de uma forma tão divertida, algo como "No mármore de tua bunda gravei o meu epitáfio. Agora que nos separamos, minha morte já não me pertence. Tu a levaste contigo" (risos). Como se vê, a morte foi tratada de uma forma tão divertida. E também ele tem poemas interessantes sobre poética. Em um deles, diz que fazer um poema é construir uma casa, mas não é um templo e nem um palácio, essa casa é construída para que você entre, por favor. Gosto das reflexões e do humor de Drummond.

Eu traduzi esse conjunto de poemas e primeiro os coloquei online. A tradução teve uma recepção muito positiva. As pessoas gostaram muito desse poeta moderno, que não conheciam ou então que conheciam muito pouco. Daí, então, alimento a ideia de continuar a traduzi-lo. Enfim, quando traduzo esse poeta, sinto que ele é mesmo brasileiro, não é americano, não é português, é brasileiro, na maneira de ser, é muito brasileiro. Você perguntou de aspecto desafiador na tradução de Drummond, mas em que sentido?

R.A.S.: Por exemplo, a língua chinesa, como você mesmo menciona em seu livro A poesia clássica chinesa: uma leitura de traduções portuguesas (Universidade de Macau, 2001), apresenta grande fluidez morfológica, permitindo, assim, que uma palavra funcione como verbo ou substantivo ou adjetivo, conforme o contexto. Essa plasticidade, essa flexibilidade morfológica e sintática do chinês, além de outras especificidades lingüísticas que não acontecem no português, interferem positiva ou negativamente quando você traduz um poema de Drummond? Ou, ainda, há especificidades lingüísticas do português e/ou singularidades na poesia drummondiana que se ofereçam como barreiras (ou desafios) no processo de tradução para o chinês?

YAO FeNG: Essa característica da língua chinesa às vezes pode tornar um poema de Drummond até mais divertido, como por exemplo: traduzi aquele poema "Quadrilha" (João amava Teresa que amava Raimundo que amava Maria...) que em chinês funciona muito bem, porque em chinês o verbo já não se conjuga, então não se sabe se Maria amava ou ama Joaquim, por exemplo, o que potencializa a ambiguidade do poema, e o torna ainda mais interessante.

R.A.S.: Mas há alguma dificuldade de que se lembre nessa transcriação de um poema de Drummond para o chinês?

YAO FenG: Como aprendi português europeu, de Portugal, então há alguns termos que, no contexto do português brasileiro, podem mudar, podem ganhar outros significados, mas eu conto consigo quando tiver alguma dúvida (risos).

R.A.S.: Além do conto "Nova Califórnia”, de Lima Barreto (1881-1922), publicado em chinês na revista "Riacho de Flores" (花溪, 1984), você traduziu outras obras narrativas? 
YAO FENG: Traduzi três ou quatro contos brasileiros. Um inclusive era de um futebolista que jogava muito bem, e a crítica central do conto era a de que o governo brasileiro gostava de usar o futebol especialmente para distrair o povo (“Adeus, Maracanã”, de Coutinho). Outro conto era sobre um homem que se casava sem parar, sempre com mulheres pouco saudáveis, sendo que todas morriam ao darem à luz, e então o homem tira partido disso, em relação a companhias de seguro, para enriquecer ("Viúvo", de Monteiro Lobato).

\section{R.A.S.: Qual a diferença, para você, entre traduzir prosa e traduzir poesia?}

YAO FENG: Como sou poeta, sinto mais agrado quando traduzo um poema, me dá mais prazer do que traduzir prosa, apesar de eu gostar muito de ler romances, ficção. Traduzir poesia, para mim, é uma aprendizagem, o que é muito vantajoso para a minha escrita. A tradução de um poema exige uma leitura aprofundada de cada termo, é preciso trabalhar detalhadamente cada palavra, cada pausa.

R.A.S.: Vamos voltar agora à primeira pergunta desta entrevista, quanto à questão do aspecto implícito em suas traduções de poemas: é o acadêmico Yao Jingming ou o poeta Yao Feng que traduz poemas do português ao chinês? Retomando a pergunta: o que determina a qualidade e o bom resultado de uma tradução de poema? Basta ser um bom conhecedor de teoria da tradução, ou precisa haver alguma experiência mais intensiva com relação à leitura e/ou à escrita da poesia?

YAO FENG: É o poeta Yao Feng que está a traduzir. Na realidade, a teoria da tradução não é nem um pouco desconhecida - de fato dediquei muito do meu tempo a ela. Sei que traduzir poesia é uma tarefa deveras difícil. Como diz o poeta americano Frost, "poesia é aquilo que se perde na tradução”. Concordo parcialmente com essa afirmação. De fato, no âmbito da poesia, há coisas que são intraduzíveis, sim, isso existe, dadas as diferenças enormes entre culturas diversas, sobretudo quando se trata da cultura chinesa com relação a qualquer cultura ocidental, o que torna a tradução de poesia uma tarefa muito difícil, um desafio muito grande para qualquer tradutor, seja chinês, americano ou brasileiro. Acredito que para traduzir bem um poema, a experiência como poeta conta muito, e também a sensibilidade desse poeta, desse tradutor-poeta, sim, no meio de um jogo tão complexo entre duas línguas, a língua de partida e a língua de chegada, que envolve aspectos polissêmicos, sonoros, visuais, gráficos etc. Portanto, é importante que o tradutor de poesia tenha experiência consistente e real entrada no mundo da poesia, e ainda, sensibilidade, consciência da sutileza das línguas, não só isso, mas também um conhecimento profundo das duas culturas com que está a trabalhar, além, claro, do indispensável conhecimento da teoria da tradução. Este último, no entanto, não é um fator decisivo para garantir uma boa tradução, mas pode tornar essa tarefa mais praticável, mais pavimentada, por assim dizer.

R.A.S.: $O$ fato de o tradutor ser um poeta, por si só, que conheça bem os dois idiomas, mas sem o conhecimento específico do ofício da tradução poética, pode garantir a qualidade e um bom resultado do poema traduzido? 
YAO FENG: Não, nada é absoluto. Olha, portanto, será que qualquer poeta pode garantir a qualidade de uma tradução de poema? Sempre depende quem é esse poeta. Será que esse poeta é um bom poeta ou não? Por isso é complicado.

R.A.S.: E você concorda que um poeta, para se tornar um bom poeta, e potencialmente, um bom poeta-tradutor, precisa construir vasto conhecimento de poesia, já que a maioria dos melhores poetas e poetas-tradutores, na história da poesia e da tradução ocidental, por exemplo, chegaram a um padrão diferenciado em sua poesia (e em suas traduções) não somente por seu talento e sensibilidade como também pela leitura sistemática de poesia e de toda sua fortuna crítica? Em outras palavras, você concorda que é preciso conhecer bem a poesia para fazer bem a poesia, assim como é preciso conhecer bem a tradição da poesia e das traduções poéticas para que se possa fazer boas traduções de poemas?

YAO FENG: Sim, por isso então, para garantir a qualidade da tradução do poema, há vários fatores; mas, olha, portanto, na prática, conheço muitos tradutores que são ao mesmo tempo poetas. Alguns são poetas muito bons, mas se calhar, como ainda não dominam totalmente a língua de partida, também falham em sua tradução; isso também acontece comigo. O bom tradutor é aquele que conhece muito bem as duas línguas (a língua fonte e a língua alvo), essa é uma condição básica, e também precisa ter sensibilidade e conhecimentos culturais, poéticos e tradutológicos. Aliás, outra coisa: traduzir poesia tem muito a ver com a personalidade e os gostos estéticos do tradutor. Não concordo que um tradutor seja capaz de traduzir todos os poetas. O bom tradutor é capaz de traduzir bem aqueles poetas com os quais tenha afinidades; se calhar, pode haver até uma semelhança de estilos de escrita, do tradutor e do poeta, um gosto ou um sabor parecido em suas escritas. Pelo menos essa é a minha experiência: quando traduzo um poeta de que gosto imenso, então posso traduzi-lo bem, porque eu gosto, porque há algo que me fascina, que me leva a trabalhar, a polir cada palavra, o ritmo, as cores das palavras, e também o silêncio, que reina nas sílabas, nos caracteres. Por isso, de fato ao traduzir, quando traduzo um verso, eu não penso tanto, há sempre uma sensibilidade, uma sutileza qualquer, que pode ser uma associação de idéias, uma espécie de intuição poética que me orienta, às vezes de forma instintiva, intuitiva mesmo; naquele momento eu não penso em teoria, mas sigo alguma sensibilidade (tanto de ordem musical quanto imagética) que me diz que tenho de traduzir assim, em vez de seguir outro caminho, outra maneira. Claro, essas “ordens” intuitivas que recebo não são nada mais que resultados da minha experiência, das minhas leituras, dos meus conhecimentos acumulados ao longo da prática e da vida. Por isso, estou sempre muito atento. Quando viajo e também na minha vida diária, gosto de observar e de avaliar tudo à minha volta, um edifício que tenha um feitio muito bonito ou feio; como aqui em Macau, por exemplo, acho o Hotel Grand Lisboa muito feio -de fato não fica muito bem naquele espaço apertado. Essa e outras observações ajudamme a treinar a sensibilidade. Há coisas belas, mas temos de ser sensíveis para vê-las. Acredito que sensibilidade é um fator muito importante para o tradutor de poesia. Essa sensibilidade, aliada ao conhecimento e à prática persistente da tradução, pode tornar o tradutor mais corajoso, mais apto a reimaginar, a reinventar, a transcriar (estou aqui tomando emprestado alguns termos do tradutor 
Haroldo de Campos) um poema de forma interessante. Se calhar, há termos muito bonitos, muito poéticos na língua de partida, mas que ao serem passados para o chinês, para a minha língua materna, ficam um bocado vulgares, medíocres; nesse caso, cabe ao tradutor tomar uma decisão corajosa, criar ou cortar esse termo na sua língua materna.

\section{R.A.S.: Então você entende o tradutor, teoricamente falando, como um transcriador?}

YAO FENG: Sim, traduzir é criar, claro. E nesse processo tradutório de recriação, o tradutor, ao longo do seu trabalho, tem sempre de ponderar, sopesar, numa prática contínua de tomadas de decisões, como mostra o teórico Jiri Levy. Em alguns casos, basta fazer uma tradução à letra, uma tradução literal, o resultado já ficará muito bom, ótimo, mas, em outros casos, o tradutor precisa criar uma coisa nova. Se calhar, uma imagem ou um verso na língua fonte é uma novidade para a língua alvo, e o tradutor, na medida do possível, deve trazer essa novidade para a língua de chegada.

R.A.S.: Que estratégias ou pensamentos teóricos a priori orientam o tradutor Yao Feng quando vai traduzir um poema?

YAO FENG: Sempre que possível, procuro manter a forma do poema, por ser um dos aspectos essenciais, o corpo do poema, por assim dizer. Essa seria uma das estratégias. A outra, não menos importante, consiste em entender o poema como um conjunto coeso, em seus diferentes níveis de entendimento, uma unidade, construída a partir de uma série de relações internas, sejam semânticas, sonoras, evocativas, gráficas etc. Outra estratégia é estar atento à letra, aos recursos que podem ser ricamente explorados a partir da literalidade do poema fonte. Em relação à manutenção da forma, claro, como há diferenças linguísticas tão grandes entre o chinês e o português, ao traduzir um soneto de língua portuguesa, por exemplo, não há como manter todas as regras rímicas e rítmicas no chinês com fidelidade; é quase impossível, mas, apesar disso, o tradutor não pode ignorar a forma, e sobretudo os efeitos musicais que esse poema traz e produz no leitor que possa lê-lo no original. Se calhar, se não for possível recriar efeitos e formas similares na língua de chegada, é preciso ao menos conseguir efeitos que correspondam, na língua de chegada, a aspectos que o tradutor possa ter percebido no poema de partida. Mesmo se não for possível manter a forma, essa é uma faceta do poema que o tradutor não deve ignorar.

R.A.S.: Você falou da importância dos efeitos musicais, da questão fônica, sonora na transcriação de um poema em outro idioma. Para perceber esses efeitos na língua fonte e para transpô-los ou reinventá-los na língua alvo, é fundamental que o tradutor saiba "escutar" atentamente o poema, mesmo que (e aqui copio uma expressão de Hans-Georg Gadamer, ao comentar os poemas de Paul Celan) somente com o "ouvido interior”. Ou seja, a questão da sensibilidade auditiva, sonora do tradutor revela-se como um aspecto de extrema relevância na tradução poética. Você comentava sobre o grande distanciamento lingüístico entre o português e o chinês, e tomou o soneto como um exemplo para falar da dificuldade e, por vezes, da impossibilida- 
de de se criar no poema traduzido efeitos similares aos do poema fonte. Vamos pensar agora em uma outra forma fixa de poema, mas pertencente à poesia chinesa, já que você também traduz do chinês para o português, ou seja, você tem as duas experiências como tradutor. Peguemos uma das formas tradicionais da poesia clássica chinesa, como o lüshi/律诗, desenvolvido no esplendor poético da Dinastia Tang (619-960), que mantém esquemas rigorosos não somente em termos de número regular de caracteres e de versos (oito versos de comprimento regular divididos em duas quadras compõem o poema, sendo cada verso de 5 ou então de 7 caracteres), como também em termos de paralelismo de versos, e, o que parece mais desafiador numa tradução, a cadência e o ritmo criados a partir de inúmeros esquemas de contraponto tonal, que são seguidos à risca por poetas como Du Fu, Li Bo e Bai Juyi. No caso, como você trabalha as sequências criadas a partir dos quatro tons do chinês (tom uniforme e tons oblíquos) numa tradução para um idioma como o português, que desconhece essas regras prosódicas? Como você faz essa adaptação musical de um lüshi para o português? Como funciona aí, na prática, essa sensibilidade musical do poeta, que você mencionou como sendo fundamental para o tradutor?

YAO FENG: De fato pra mim, traduzir da minha língua materna para o português é mais difícil ainda, porque, conforme a teoria da tradução, o tradutor deve traduzir mais de uma língua estrangeira para sua língua materna. Por isso, sim, quando eu era jovem, se calhar, eu tinha mais coragem de traduzir poema chinês para o português. Hoje em dia, com a idade, eu fiquei com mais medo de traduzir da minha língua materna para o português. De fato é difícil. Então, se quisermos discutir a tradução de um lüshi, acabaremos falando novamente daquilo que se perde na tradução, pois essa forma poética, como você já mencionou, segue regras rigorosíssimas. Para atingir um nível de perfeição, isto é, para compor um lüshi perfeito ao nível da forma, o poeta precisa ser treinado durante muito tempo. Portanto, ao traduzir um poema chinês, rigoroso em sua forma, para o português, se o tradutor almeja recriar padrões formais muito similares na língua alvo, isso, sim, é impossível. Passar forçosamente padrões tonais para o português não vai funcionar de forma alguma. É semelhante ao que acontece na tradução de um soneto, uma das formas clássicas da lírica portuguesa, para a língua chinesa. As rimas, o esquema de estrofes do soneto, entre outros elementos, engendram um jogo muito harmonioso, perfeito, mas difícil de ser traduzido, porque o soneto não deixa de ser um fruto das características específicas da língua portuguesa, e o mesmo eu diria da relação do lüshi com a língua chinesa. São raros os casos de sucesso nessas traduções de poesia clássica que procuram manter, de forma muito rigorosa, os mesmos paralelismos dos poemas originais. Portanto, quase sempre há grandes perdas nessas traduções, e por isso o tradutor deve estar atento para conseguir também ganhar nesse processo. Na verdade, a tradução é mesmo um jogo de perdas e de ganhos, e o tradutor tem que ter coragem de perder alguma coisa mas também de ganhar em outro aspecto, para compensar o jogo, que, quando se trata da tradução de um poema clássico é muito mais difícil de ser jogado. Como a nossa língua não é alfabética, cada sílaba é em si uma palavra, por isso, se um verso clássico apresenta sete caracteres, ou sete palavras cheias, sem preposições, por exemplo, será complicado conseguir recriá-lo com sete palavras em apenas sete sílabas no português... E 
ainda sem mencionar as típicas omissões de sujeitos, de advérbios etc nos poemas clássicos chineses, que quase sempre são irrecriáveis em português. Mas, se estivermos a falar da poesia moderna, quando traduzo um poema de Carlos Drummond de Andrade, que é um poeta moderno, não preciso respeitar essas regras, economia vocabular e o rigor do lüshi, já que o ritmo da poesia moderna é livre, não necessariamente ditado por padrões rígidos de composição. Na poesia moderna, cada poeta tem o seu ritmo próprio, a sua respiração. É mesmo como um ritmo de respiração. Há poetas que procuram fazer versos muito longos, com fôlego maior, muito prolongado; se calhar, ele gosta de respirar assim. Eu quase sempre componho versos curtos, quando um verso ultrapassa 15 caracteres já sinto dificuldades de respirar (risos). Ao traduzir um poema moderno, vou procurar recriar o ritmo e as formas que percebo no poema original, vou buscar manter minha tradução o mais próximo possível do poema original, mas, em caso de necessidade, permito-me alterar a forma ou o ritmo. Outro ponto, com relação às rimas: ao traduzir, com freqüência tenho de abrir mão das rimas, pois rimar, por vezes, é perigoso. Se o tradutor não rimar bem, o poema pode tornar-se um pouco ridículo, pelo menos em chinês. Nesse caso, procuro compensar nos comprimentos dos versos e no ritmo do poema, nas pausas entre as palavras e as linhas. Quanto ao poema moderno chinês, por exemplo, se um verso tem muitas palavras, provavelmente será preciso quebrá-lo em sua versão portuguesa, criar uma linha adicional.

R.A.S.: Você tinha falado da importância da sensibilidade do tradutorpoeta ao fazer uma tradução de poema, e contou que, quando viaja, procura aproveitar ao máximo o visual, as coisas que você vê ao seu redor, a arquitetura, a publicidade, pois a percepção e a leitura desses elementos contribuiriam para apurar sua sensibilidade. Certo, mas até aí você está se referindo a uma sensibilidade visual, às imagens. $E$ quanto à sensibilidade auditiva, sonora, como ela pode ser treinada, desenvolvida pelo tradutor?

YAO FENG: Se calhar, não sou tão sensível para esse aspecto sonoro, porque não tenho jeito para cantar, para dançar... (risos)

R.A.S.: No papel de tradutor, como você lida com as diferenças entre uma língua fonética, como o português, e uma língua que apresenta uma etimologia visual, como o chinês? Ao ler um poema em chinês, ou ao traduzir um poema para o chinês, qual a importância das imagens gráficas possivelmente contidas nessa escrita chinesa, que, para Fenollosa, consiste em um meio para a poesia? ${ }^{3}$ Gostaria de saber se você costuma explorar esse aspecto visual dos caracteres ao traduzir e ao escrever um poema.

\footnotetext{
${ }^{3}$ O orientalista americano Ernest Fenollosa (1853-1908) escreveu o ensaio The Chinese Written Character as a Medium for Poetry, publicado pela primeira vez por Ezra Pound em 1919. Ao comparar o sistema fonológico de escrita ocidental com o sistema da escrita chinesa, de etimologia constantemente visível, Fenollosa escreve que a língua chinesa “conserva a seiva primitiva, não é como um galho seco [no caso, a escrita fonológica] que serve de bengala [de sons que vão evocar palavras, que, por sua vez, poderão evocar imagens]” (Fenollosa, p.129). O potencial imagético da escrita chinesa, na visão de Fenollosa, é em si um instrumento para a poesia, que, em sua essência é feita de imagens, como grande parte dos caracteres chineses. $\mathrm{O}$ ensaio teve fundamental importância para as vanguardas poéticas do século XX, especialmente para o imagismo poundiano.
} 
YAO FENG: A nossa língua chinesa gosta muito de recorrer às imagens, às metáforas para expressar uma ideia Olha, portanto, quando se descreve a beleza feminina, uma mulher muito esbelta, com bom corpo, boas linhas e gestos muito bonitos, isso em geral é feito por meio de metáforas, como a do peixe, por exemplo. Esta mulher, com linhas, roupas e gestos tão bonitos, pode ser descrita como o peixe que mergulha no fundo da água. Por isso, quando escrevo um poema ou quando traduzo, essas imagens, essas marcas, embora não de forma tão direta, podem aparecer na minha escrita.

\section{R.A.S.: Nesse caso, da metáfora do peixe para descrever a beleza de uma mulher, isso poderia aparecer em seu poema dado ao fato de você ter esco- lhido caracteres chineses relacionados graficamente a imagem do peixe?}

YAO FENG: Não, mas é assim, às vezes tem de se evitar o estereótipo. Olha, essas metáforas, já discutidas em tantos ensaios e artigos, podem ser interessantes para vocês, mas para nós, como já são imagens tão recorrentes, se calhar, devem ser evitadas, pois já não trazem nenhuma novidade para a nossa língua. Pode ser que essa imagem, em português, seja tão gira, tão diferente, que bastaria fazer uma tradução direta para mantê-la. Sim, como acontece em algumas traduções minhas, a exemplo de um poema de Eugénio de Andrade, em que descreve as gaivotas pairadas no céu como se fossem uma coroa, é uma imagem lindíssima, por isso então fiz uma tradução literal, e funcionou muito bem em chinês. Os poemas de Eugênio de Andrade são muito musicais, e eu busco recriar esse aspecto na minha língua materna. Essa imagem da coroa foi muito elogiada pelos leitores chineses, por ser uma imagem bonita, surpreendente e nova. Quanto às imagens contidas na escrita chinesa, somente uma porcentagem pequena dos caracteres são pictogramas, como pássaro, montanha, água etc. Alguns caracteres incorporaram ideogramas. Os ideogramas junto com caracteres tornam um caractere novo, como o mar (海), que é composto por 3 traços curtos, referentes à água e a um outro elemento qualquer, que juntos então viram "mar”. A névoa é uma composição de montanha mais vento (岗). Nuvem na montanha, é uma névoa que rodeia uma montanha, um termo lindíssimo. Tudo isso portanto dá uma visão, uma imagem visual, mas, na tradução, não é uma questão a que sempre dou importância. São meros caracteres. Portanto, eu não escolho esse ou aquele ideograma porque poderá trazer uma imagem gráfica, não, a minha preocupação é mais ao nível semântico e sonoro. Sim, o aspecto semântico e sonoro, como no português, que se pode escolher entre pássaro, ave ou passarinho, o que tem de ser considerado de acordo com o contexto. Ave pode ser melhor, pois é mais curto, tem menos sílabas, mas, noutro contexto, pássaro pode soar melhor do que ave. A questão visual dos caracteres, quando traduzo um poema, não é a mais importante. Não é. Para vocês, se calhar, é uma coisa de exotismo, mas no nosso dia a dia não é uma questão muito importante. Então, pássaro é pássaro, esse caractere tem uma imagem visual, mas para nós não é uma coisa muito importante. 
R.A.S.: Um poema que você escreva ou traduza para o chinês será lido por pessoas de diferentes dialetos por toda a China. Um chinês de Macau ou da região de Cantão, que tenha o cantonês como seu dialeto, mesmo que conheça bem o mandarim (adotado na China como dialeto oficial), dará a esse seu poema, mesmo que não o leia em voz alta, a sonoridade do cantonês, que tem seu sistema tonal próprio e é um dialeto tão diferente do mandarim. Você, ao escrevê-lo, projetou seus esquemas sonoros e tonais em mandarim, que é seu dialeto nativo. O seu poema, lido por esse chinês de Cantão, resultaria num outro poema? Ainda que os sentidos e as imagens contidas em seu poema possam ser perfeitamente compreendidas por esse chinês, sua recepção sonora será outra, e a unidade do poema, como se sabe, resulta de um conjunto de imagens, formas, entre diversos outros elementos, e... som.

YAO FENG: Não, não, não, não seria outro. Seria o mesmo poema, só que poderia ser declamado em diferentes formas.

R.A.S.: $\mathrm{O}$ fato de seu poema ser declamado em diferentes dialetos, como o cantonês e o hokkien, por exemplo, poderia torná-lo inferior ou até mesmo superior do que quando declamado em mandarim?

YAO FENG: Não. Acho que não afeta muito, pois em geral um poema é lido sem voz, então um poema bom é um poema bom, ele não depende de ser lido por uma voz muito boa para que se torne bom, não.

R.A.S.: Mas se você tiver trabalhado com rimas internas em seu poema, ou mesmo rimas em finais de versos, para dar um exemplo simples, esses efeitos podem se perder quando o poema é lido, por exemplo, em cantonês, não acha?

YAO FENG: Sobre esse aspecto sonoro, no entanto, não só eu, mas todos os poetas chineses, talvez tenhamos de nos esforçar mais para tornarmos um poema melhor, porque esse é um aspecto quase sempre negligenciado.

R.A.S.: Mas quando você está escrevendo um poema, Yao, você certamente está "escutando" o que escreve, o que cria, você está imprimindo cadência, ritmo, silêncios etc, ou seja, o som não parece em hipótese alguma negligenciado.

YAO FENG: Sim, o som é importante, mas eu não trabalho muito com esse aspecto. Portanto, é assim: primeiro eu penso nas imagens e no que quero dizer num poema, e depois então de completar aquilo que quis dizer, a minha ideia, é que passo a pensar no aspecto sonoro do poema, como por exemplo, o primeiro verso, em vez de ter oito caracteres, deve ter quatro etc. Um poema muito medíocre, mesmo que lido por uma voz bonita, continua medíocre. O som ajuda a tornar o poema mais bonito, ao ser ouvido, mas, hoje em dia, em vez de ouvir, sentimos os seus aspectos sonoros. De fato estamos a perder essa tradição de declamar, de recitar poesia. 


\section{CARLOS DRUMMOND DE ANDRADE}

O mundo é grande

O mundo é grande e cabe nesta janela sobre o mar. O mar é grande e cabe na cama e no colchão de amar. O amor é grande e cabe no breve espaço de beijar.

Tradução de Yao Feng:

\section{世界很大}

世界很大，

但这扇向海的窗子可以把它容纳。

大海很大

但这张床、这个爱的床裖可以把它容纳。

爱情很大，

但一个亲吻可以把它容纳。

(tradução livre)

世界很大

Mundo/muito/grande

世界/很/大

Mundo/muito/grande

但/这扇/向/海/的/窗子/可以/把它/容纳。

Mas/esta/virado/mar/janela/pode/ele/caber

大海很大

Mar/muito/grande

但这张床、这个爱的床裖可以把它容纳。

Mas/esta/cama/esta/amar/colchão/pode/ele/caber

\section{爱情很大}

Amor/muito/grande

但一个亲吻可以把它容纳。

Mas/um/beijo/pode/ele/caber 
Yao Jing Ming

jmyao@umac.mo

Prof. Dr., Universidade de Macau

Raquel Abi-Sâmara

raquelmag@umac.mo

Profa. Dra., Universidade de Macau

\section{Referências bibliográficas}

Abreu, António Graça de. "Prefácio”, in Poemas de Bai Juyi. Tradução, prefácio de notas de António Graça de Abreu. Macau: Instituto Cultural de Macau, 1991. Coleção Clássicos Chineses.

Cheng, François. "A escrita poética chinesa”. In: Revista de Cultura (RC) n. 25 (II série). Edição em Português. Macau: Instituto Cultural de Macau (ICM), Outubro/Dezembro 1995. Título da RC: A arte poética da China. Tradutores lusíadas de poemas chineses. Macau na poesia.

FENOLLOSA, Ernest. "Os caracteres da escrita chinesa como instrumento para a poesia”. In: CAMPOS, Haroldo de. Ideograma. Lógica, poesia, linguagem. São Paulo: Edusp, 2000. pp.109-148

Jingming, Yao. “Traduzir um Poema: Por Ser Poema e Para Ser Poema”, in Textos e Pretextos $\mathrm{N}^{\circ}$ 15. Lisboa: Universidade de Lisboa, Livro do Dia, 2012. pp. 147-149.

. A poesia clássica chinesa: uma leitura de traduções portuguesas. Macau: Universidade de Macau, 2001. Coleção Estudos de Macau. 